\title{
Moral dilemmas in surgical training: intent and the case for ethical ambiguity
}

\author{
Michael J Newton Mount Sinai School of Medicine, New York
}

\section{Author's abstract}

It is often assumed that the central problem in a medical ethics issue is determining which course of action is morally correct. There are some aspects of ethical issues that will yield to such analysis. However, at the core of important medical moral problems is an irreducible dilemma in which all possible courses of action, including inaction, seem ethically unsatisfactory. When facing these issues ethical behaviour depends upon an individual's understanding and acceptance of this painful dilemma without recourse to external moral authority.

As a physician actively involved in training surgeons I frequently face the moral dilemma of how the inexperienced are ethically to acquire their skills. The burgeoning medical ethics literature at first seems to provide both a general frame of reference in which to view this problem and specific guidance in the field of patients' rights. Closer examination leads me to the conclusion that at the centre of this problem is a dilemma which forces each trainee and instructor to take individual responsibility for the morality of his or her action. Furthermore, while reliance on external ethical guidelines may initially seem helpful it ultimately becomes deeply destructive of the ability to develop this sense of ethical intent which requires a constant, painful awareness of how we affect the lives of others.

The most frequently performed ophthalmic surgery is cataract extraction, and by looking at the specific details of this procedure the ethical considerations become evident. If the surgical instructor could exercise complete control over the trainee at each step of the procedure or fully correct any problems that arose then the patient would, in essence, be under the care of the fully trained physician. Such is not the case. Several of the most delicate and critical manoeuvres involved in removing the cataractous lens are under the complete control of one operator and, once begun, can be neither interrupted nor transferred to more skilled hands. If the trainee is to learn cataract surgery he must at some time in his career begin performing these all-

\section{Key words}

Medical ethics; medical ethics in surgical training. or-none manoeuvres. It is at these times that the question arises whether the patient's medical care is ethically acceptable.

The instructor can, of course, help to correct errors made by the trainee. However, it must be understood that such counter measures are always second best to 0 performing the manoeuvre correctly the first time. It should also be clear that while ophthalmic microsurgery presents a plethora of all-or-none steps ${ }_{\Gamma}^{\mathbb{D}}$ the excessive handling of tissues and the time delays $\frac{\mathscr{}}{3}$ encountered in correcting mistakes adversely affect the surgical results and anaesthetic risks of any procedure. Moreover, this same ethical problem arises in a less $\vec{\varnothing}$ dramatic but equally perplexing way in non-surgiege्, 1 \% training. One example is the performance of painfulo and diagnostically critical tests (for example spinal tap, endoscopic examinations) by the trainee with the instructor supervising. While there are instances in which health-care professionals at various levels of training benefit the patient by acting as a team, there $\stackrel{2}{\rightleftarrows}$ can be no instance in which immediate care of the $\frac{0}{3}$ patient is best left to the least skilled. In what ethical framework, then, is one to place the actions of the ophthalmic surgical trainee as he performs his initial operations?

When confronting this question the resident trainees $\stackrel{\mathbb{D}}{-}$ themselves usually offer a disarmingly simple answer; I am here to learn surgical skills which must, one way or another, be perpetuated. Such a trainee thus actually sees no ethical conflict at all in his work. Upono closer examination, however, this line of reasoning is simply a belief that the end justifies the means. In theo context of our discussion this is essentially a suggestion that the individual's right to the best available care canor be subordinated to the more general need for skilled N physicians in the future. Is this correct?

Turning to formal medical ethics for guidance we $\omega$ encounter opinions that are at once contradictory with one another and internally inconsistent. An example of the latter is the frequently invoked Declaration of $f$ Geneva. This oath, which is felt by many to be less 0 antiquated and more appropriate than the Hippocratico vow, was offered at my own medical school graduation. $\overrightarrow{\mathbb{D}}$ The declaration sets as its opening premise a general $\overrightarrow{\mathbb{D}}$ 'service of hmanity' (1). But it then states the 'the health of my patient will be my first consideration'. 
These two goals are mutually exclusive when the least skilled operator must perform critical steps in order to perpetuate the surgical art.

The medical ethics texts often divide the more classical moral teaching into utilitarianism, as personified by the works of John Stuart Mill, and the deontological philosophies as exemplified by the writings of Immanuel Kant (2). The utilitarians would presumably favour an ethical choice that led to the greatest good for the greatest number of people. This would seem to support the ethics of surgical training. However, weighing the long-term societal costs and benefits of each individual action is a very nearly impossible task and the utilitarians are open to the charge that errors will result in violation of the rights of individuals, respect of which is necessary also if welfare is to be maximised. Philosophers exemplified by Kant stress that ethical action lies in the wilful following of moral absolutes regardless of the potential consequences. Foremost among these 'categorical imperatives' is the admonition to 'act so that you treat humanity, whether in your own person or in that of another, always as an end and never as a means only' (3). Such a philosophy certainly would seem to render unethical a situation in which the less qualified surgeon performed critical steps in the hope of promoting a greater general good - unless of course the patient has willingly and knowingly accepted that he or she might be operated on by a trainee - but given the option of having an important operation performed by a fullytrained surgeon or his assistant-in-training how many patients would willingly accept the latter? The absolutist approach however, if it insists on fully informed consent to operation by a trainee would greatly impair surgical education and thus does not address the perceived moral obligation to pass on surgical skills for the benefit of future patients. In fact, it seems to buy a temporary ethical respite at the expense of those individuals who will eventually need the care of the trainee.

This is a very brief review of some of the lines of ethical thought that can be brought to bear on the problems of surgical training. My purpose is simply to illustrate that the situation faced in the operating room is a true ethical dilemma and that attempts to set the trainee's actions within traditional guidelines fail. Indeed, it seems that the trainee's performance of the critical surgical manoeuvre is at once both morally correct and incorrect. There is a natural tendency to view such a situation as being hopelessly unclear and to act as though no ethical standards apply and no ethical input can be achieved.

I believe that when analysing such moral ambiguity we must begin by accepting the fact that the specific action taken is in itself ethically neutral. That is, correctness can lie neither in performing nor in abstaining from the action. Thus, if ethical standards are to apply, which is clearly so, they must arise totally outside the act itself. The source of this ethical input can only be the intent of the surgical trainee.
Performed with correct intent these actions are ethically acceptable, without it they are not.

But what is 'correct intent' and how is it developed? Surely it is much more than simply wanting to do the right thing. Correct intent is primarily an ethical sensibility that rests upon a constant and often painful awareness of the consequences inherent in human interaction. For example, the surgical trainee is happily aware that most of his patients will benefit from his actions most of the time. It is more painful also to hold the awareness that when performing the all-ornone steps adverse results might arise, that the forces placing him in the role of surgeon rather than patient are at best unclear and that future financial rewards provide a portion of his motivation. It is certainly more comforting for the trainee to fall back on the premise that since surgical training must go on, some patients' individual rights simply must be subordinated: the trainee is in essence freed from all ethical responsibility.

If it is true that the surgical resident faces an insoluble dilemma then why should painful emotions akin to guilt arise? The reason is that similar insoluble issues lie at the centre of all ethically demanding situations. Issues such as euthanasia, abortion and animal experimentation for example, present a similar set of unresolvable choices. At the core of each is an allor-none action both the performance or omission of which will have unwanted effects. Opposing sides often try to decide the issue by recourse to regulations while denying that equally painful consequences must then arise. The core decision (to hasten death, to abort, to inflict discomfort on animals), should in fact remain painful.

Indeed those questions of human action that can be resolved by external ethical guidelines can often just as well be resolved by recourse to the Golden Rule. The core dilemmas defy philosophical resolution and make us confront the fact that each of our options will cause pain or harm. To the extent that we attempt to deny our participation in that pain or harm by claiming that external guidelines mandate one course of action we diminish the sense of ethical intent.

The consequences of such a loss of ethical intent can be seen in the training of cataract surgeons. The trainee is required to begin by observing others perform cataract operations, to read about the procedures, to practise the procedure on cadaver eyes and to participate in the post-operative care of patients. More general regulations concerning the total number of hours per week that must be devoted to the training programme and various examinations that must be passed are also usually in effect. All of these guidelines attempt to make the trainee's action ethically acceptable and can be imposed in the complete absence of an ethical intent. The surgical resident may consider these regulations to be definitive and will assume that by adhering to them his actions are 'certified ethically correct' and require no further moral input, especially when confronting the all-or-none dilemma. But having 
come to believe that external guidelines can ensure ethical behaviour the young surgeon may greatly abuse his position, for many questions will arise that can only be addressed by correct intent. For example, how much of his otherwise free time must be devoted to reading and to practising surgery in the laboratory? When is he or she ready to progress to more difficult operations? Should a scheduled case be performed with a substitute teacher if the most appropriate surgical instructor becomes unavailable? Should subspecialty procedures (for example corneal transplantation, retinal detachment surgery) be performed if the trainee's plans suggest that he may not do this particular operation in the future? A trainee imbued with a sense of ethical intent will realise that these questions are addressed in the context of simple daily choices ranging from how much free time can be devoted to a relaxing hobby to the ability honestly to pick the appropriate instructor for a given operation. The correctly motivated trainee will see that ethical behaviour is expressed in this continuing way and not by hiding under the umbrella of grand conceptual schemes such as presumably honourable medical training or abstract religious and philosophical doctrines.

It is interesting to note that both Kant and Mill recognised the presence of moral dilemmas and the inescapable need for an ethical intent. Kant called it the 'good will' without which 'nothing in the world . . . can possibly be conceived which could be called good' (4). Mill refers to the 'virtue' needed to deal with moral dilemmas, and it is interesting to quote him at length.

'There exists no moral system under which there do not arise unequivocal cases of conflicting obligation. These are the real difficulties, the knotty points both in the theory of ethics, and in the conscientious guidance of personal conduct. They are overcome practically with greater or less success according to the intellect and virtue of the individual; but it can hardly be pretended that any one will be the less qualified for dealing with them from possessing an ultimate standard to which conflicting rights and duties can be referred' (5). [emphasis added]

My feelings may be summarised by pointing out why the last phrase of this quotation does not at all follow as a truth. When there is 'unequivocal ... conflicting obligation' requiring 'intellect and virtue' then the ability to act correctly will most certainly depend upon an individual's having developed a personal sense of ethical intent free from the reliance on external authority. The attempt to find an 'ultimate standard' is inherently self-deceptive and thus deeply destructive to an inner ethical sensibility.

Of what value, then, is the study of medical ethics? A systematic approach will help guide our actions in? the unambiguous aspects of an ethical problem. Such an approach can, for example, make explicit theo surgical trainee's responsibility to minimise risks to his patients. More important, however, is the ability to usen ethical training to see the limits of codes, laws and rulesథ of behaviour. A clear analysis of each ethical problem will move us compellingly towards the central dilemma ${ }^{\text {s }}$ which will be unresolvable in an abstract philosophicale way. Representing nothing less than our inevitable $\overrightarrow{-}$ involvement in the dynamic commotion and harsh vagaries of life, this core dilemma will present us withs painful choices. If we deny our involvement bỵ̣ refusing to remain ethically aware when facing the corev dilemma, then we are attempting to live a moral life on a part-time basis. Such a limited commitment inviteso complete failure.

Painful choices, as exemplified by the issue of $\stackrel{\circ}{\circ}$ surgical training, are not a cause for despair. $\vec{\nabla}$ Immorality seems to me to lie in abandoning one's owno counsel at precisely such moments and seeking relief in external authority. Instead, one can see the core dilemma as the opportunity for the fullest expression of moral behaviour. Thus, we can turn from the inviting $\overrightarrow{0}$ arms of apathy and cynicism and continue to perfognos as though a good outcome could be assured by ogr actions, even though it clearly cannot. This refusateon flee from personal responsibility, while remaining painfully aware of the inevitability of adverse consequences, seems to me to lie at the heart of ethicalo behaviour.

Michael Newton $M D$ is in the private practice of ophthalmology in New York City and is Assistant Clinical Professor in the Department of Ophthalmology at The. Mount Sinai School of Medicine and Assistant Attending Surgeon at the Manhattan Eye, Ear and Throat: Hospital.

\section{References}

(1) McConnell T C. An introduction to medical ethics. Monterey: Wadsworth, 1982: 267.

(2) Beauchamp T L, Walters L, eds. Contemporary issues in bioethics, 2nd ed. Belmont: Wadsworth, 1982: 13, 19.

(3) Kant I. Foundations of the metaphysics of morals Indianapolis: Bobbs-Merrill, 1981: 47.

(4) See reference (3): 9.

(5) Mill J S. Utilitarianism. In: Essential works of fohn Stuar Mill. New York: Bantam, 1965: 212. 